\title{
NO'IES ON CERTAIN REACTIONS FOR TYROTOXICON.
}

\author{
By H. A. Weber, Ph. D.
}

(Prof. Agricult. Chem. Ohio State University, Columbus, O.)

Through the Ohio State Board of Health and the Ohio State Dairy and Food Commission the writer has, within the last few years, received numerous samples of poisonous cheese for examination. The samples were tested for tyrotoxicon according to the well known method as published by Dr. Vaughan. About 1,500 grammes of the cheese was cut up into small cubes, placed into a percolator, covered with distilled water and allowed to digest at ordinary temperatures for several hours. 'The aqueous extract was then withdrawn and more water added, a little at a time, until abont one litre of percolate was obtained. This was rendered alkaline with sodium carbonate, extricted with half its volume of Squibb's ether and the ether allowed to evaporate spontaneously. After complete evaporation of the ether the aqueous residue was subjected to the following tests:

One drop was added to a mixture of ferric chloride and potassium ferricyanide. In all cases an immediate precipitate of prussian blue was formed.

One or two drops were added to a mixture consisting of a few drops each of carbolic acid and strong sulphuric acid. A reddishyellow coloration ensued in all cases. On standing for several hours this color changed to permanent violet.

The remainder of the aqueous residue was, at a single dose, given to a small kitten. In no case could any ill effects be observed. Since tyrotoxicon has been shown by Dr. Vaughan to be such an active poison, and since the physiological test in all cases examined by the writer have been signal failures, it was concluded 
that the reactions mentioned above must have been due to other causes. In looking for these causes, it was found that commercial butyric acid could be made to produce both reactions in a satisfactory manner, as will be seen from the following tests:

A single drop of the butyric acid produced only a slight formation of prussian blue when added to a mixture of ferric chloride and potassium ferricyanide. With a single drop of the butyric acid, the carbolic acid reaction was very marked, the mixture immediately turning bright orange red, and changing to dark violet on standing.

One-half cubic centimetre of the butyric acid was mixed with $50 \mathrm{c.}$ c. of water and filtered. The filtrate was rendered strongly alkaline with sodium carbonate, extracted with ether and the ether was allowed to evaporate spontaneously. 'The aqueous residue gave both reactions with marked distinctness.

Again, the last sample of cheese examined was allowed to remain in the percolator. The bottom of the percolator was corked, the cheese covered with distilled water and the mouth of the percolitor covered with a glass plate. After standing four or five days further, decomposition had set in. The aqueous extract was then withdrawn and filtered. The filtrate was alkaline and had an offensive odol. It was placed in a flask comnected with a condenser and a portion distilled over. This was done to detroy any tyrotoxicon that might have been present. The distillate was very alkaline and hiad a strong, sickening odol of herring brine, probably due to trimethylamine. From tlis distillate both reactions were obtained, the prussian blue reaction being especially marked.

'The residne left in the fiask was removed, acidulated with sulphuric acid and filtered. The filtrute was again subjected to distillation. The distillate was acid and had a strong odor of butyric acid. It gave no prussian blue reaction and only a faint one with carbolic acid. A portion of this distillate was rendered alkaline with sodium carbonate and extracted with ether. The residue gave no reaction whatever with carbolic acid, owing evidently to the fact that the sodium butyrate is insoluble in ether. The remainder of the acid clistillate was then nixed with the alkaline distillate obtained above. The mixture was rendered alkaline 
with sodium carbonate and then extracted with ether. 'The aqueous residue now gave both reactions very distinctly.

From these experiments it may be inferred:

1. That the prussian blue reaction is caused by the presence of an organic base, probably an amine.

2. That the carbolic acid reaction is due to butyric acid.

3. That, when both bodies are present in the same liquid both are extracted with ether from an alkaline solution, probably in the form of a butyrate of the organic base.

4. That both bodies are liable to occur in any old specimen of cheese, milk or cream.

5. 'That the presence of there two bodies causes artificial diazobenzole to give the orange red reaction with carbolic acid, after being extracted from whey with ether, which it does not give before. 